\title{
Influence of an Increased Fiber Filler Content on the Elongation Behavior of Filled Films in the Thermoforming Process
}

\author{
Lisa-Maria Wittmann*, Michael Wolf, Dietmar Drummer \\ Institute of Polymer Technology, Friedrich-Alexander-University, Erlangen-Nuremberg, Germany
}

Email address:

wittmann@lkt.uni-erlangen.de (Lisa-Maria W.)

${ }^{*}$ Corresponding author

\section{To cite this article:}

Lisa-Maria Wittmann, Michael Wolf, Dietmar Drummer. Influence of an Increased Fiber Filler Content on the Elongation Behavior of Filled Films in the Thermoforming Process. American Journal of Mechanical and Materials Engineering. Vol. 3, No. 2, 2019, pp. 25-35. doi: 10.11648/j.ajmme.20190302.11

Received: May 15, 2019; Accepted: June 15, 2019; Published: June 26, 2019

\begin{abstract}
Thermoforming belongs to one of the most important processes in polymer processing, especially in the packaging industry. It enables the forming of thermoplastic components into shaped parts at high temperatures. Since the thermoforming of films takes place in the rubbery state, amorphous thermoplastics are mainly processed, which have a wide rubbery state. Radiation crosslinking can be used to widen the thermoforming window of semi-crystalline thermoplastics. A benefit of the crosslinking is the increased short-term temperature resistance. In general, there are only a few investigations concerning the thermoforming of filled thin films. Within this investigation, the influence of an increasing glass fiber content up to 15 vol.- $\%$ as well as the effect of radiation crosslinking on the elongation behavior and the wall thickness distribution was examined. It can be summarized that especially thermoforming with an increased filler content at high areal draw ratios represents a challenge. Whereas non-crosslinked glass fiber filled films are thermoformable only at low areal draw ratios, radiation crosslinked films can be also formed at higher areal draw ratios without difficulties. For high filler contents and high areal draw ratios, no forming is possible at high areal draw ratios, although the films have been crosslinked. The use of radiation crosslinking enables the process limit in thermoforming of thin filled films to be increased and thus the range of applications to be extended greatly.
\end{abstract}

Keywords: Glass Fiber, Radiation Crosslinking, Elongation Behavior, Wall Thickness Distribution, Thermoforming

\section{Introduction}

Thermoforming belongs to one of the most important processes in polymer processing, especially in the packaging industry [1]. It enables the forming of thermoplastic components into shaped parts at high temperatures [2]. The thermoforming process is divided into four main processing steps [3-4]. First, the film product is heated to its forming temperature and the forming is conducted by using a thermoforming tool. Male or female tools can be used. In the case of a male mold, the forming process is carried out using a convex mold. Contrary, a concave shape of the mold is called a female mold [2-3]. Typical mold materials are aluminum or steel, which are heated and prevent rapid cooling of the molded part [2-3]. The mold temperatures can vary between $10^{\circ} \mathrm{C}$ and $100^{\circ} \mathrm{C}$, depending on the polymer used. For high-density polyethylene, a mold temperature of $100^{\circ} \mathrm{C}$ is used [2-3]. After the forming process, the molded part is cooled under form constraint. Since the thermoforming of films takes place in the rubbery state, amorphous thermoplastics are predominantly processed, which have a wide rubbery state. Polystyrene (PS) is used, for example, in the production of displays and refrigerator door panels [2]. Acrylonitrile-butadiene-styrene (ABS) is mainly applied for the production of technical components such as containers or housings due to its good impact strength and heat resistance. Thereby ABS is characterized by its wide processing temperature range [3-5]. Furthermore, there is a direct correlation between increased melt stiffness and reduced sagging. The higher the melt stiffness, the lower 
the sagging during the heating phase [5]. Semi-crystalline thermoplastics generally demonstrate low melt stiffness. Thus, only standard thermoplastics such as polypropylene (PP) or polyethylene (PE) are used usually for the thermoforming process [3]. The sagging represents a risk for machine components, like radiant heaters, as the polymer can drop off and thus damage the radiators. It is known that an increased crosslinking increases the melt stiffness of polymers [6-7]. Chemical reaction or irradiation can be used to crosslink thermoplastics. The crosslinking takes places in amorphous regions of the polymer. Radicals that are induced by the radiation are recombined leading to chain branching and therewith to the formation of a three-dimensional network of macromolecules. A benefit of the crosslinking is the increased short-term temperature resistance [8], which can be used especially in the thermoforming of semicrystalline thermoplastics. In order to induce radiation crosslinking in semi-crystalline thermoplastics, an additive is usually required to start the crosslinking reactions. PE is one of the only materials that can be crosslinked without the addition of crosslinking agents [8-9]. In the thermoforming process, there are a number of factors that influence the final quality of the formed film. Among other things, the final product quality is mainly determined by a homogeneous wall thickness distribution [10-14]. Thermoforming of reinforced components is mainly known from the area of fiberreinforced thermoplastics. In the automotive industry fiber reinforced parts are used for example as door structures [15]. There is a number of investigations dealing with the influence of laminate sequences on forming behavior. Lebrun et al. [16] and Lussier et al. [17] for example figured out that the laminate temperature, pull-out velocity and pressure have an influence on the interlaminar shear strength of continuous glass fiber reinforced polypropylene. In addition to the viscosity state of the matrix, the fabric structure also influences the forming behavior as it is shown by Lussier et al. [17]. Here, it has been demonstrated that an increasing number of crossover points leads to an increasing load and material stiffness. A plane weave orientation of the fibers seems to have a high influence on the thermoforming quality [18]. According to Behrens [19], a glass fiber orientation at an angle of $-45^{\circ} /+45^{\circ}$ is found to be most suitable for the thermoforming with organo sheets consisting of polyamide 6 as matrix. It is difficult to transfer the results from the forming of organo sheets to the thermoforming of thin filled films, because extruded films only have a filler orientation depending on the extrusion direction, so that specific investigations on the forming behavior of thin filled sheets are needed.

In general, there are only few investigations concerning the thermoforming of thin filled films. As main factor influencing the forming behavior, the particle size, particle geometry, interactions of filler and matrix or particle distribution can be named [20]. The bonding between filler and matrix is mainly influenced by physical interactions and mechanical bonding [20]. Even if the influence of fillers on biopolymers, which are processed in the thermoforming process, is worked out in [21-22], the main focus in this investigations is not on the influence of the particle shape on the forming behavior, but more on the general feasibility and material behavior. Mohan et al. [21] found out that the thermoformability of films consisting out of corn starch and filled with montmorillonite-based nanoclay fillers is improved by adding $2-3$ wt.- $\%$ nanoclay concentration as the dispersion of the nanoclay particles in the films is good. However, no characterization of the thermoformed components such as wall thickness changes or elongation behavior after the forming process was carried out. Only a basic suitability of the material for the thermoforming process was performed on the basis of material characterizations. By analyzing the wall thickness distribution and strain development, an evaluation of the quality of the final component could be conducted and, for example, weak points by extreme wall thickness thinning can be identified. In [23] the thermoformability of the biopolymer polyhydroxybutyric acid (PHB) filled with almond shells, rice hush and seagrass was investigated. Especially with an addition of 10 weight percent almond shells an extension of the thermoforming capability could be detected. The good formability of PHB filled with almond shells can be explained by the prevailing aspect ratio of 2 and a particle size of $45 \mu \mathrm{m}$. According to the author, the other particles used had a size of $70 \mu \mathrm{m}$ (rice hush) and 25-200 $\mu \mathrm{m}$ (seegrass) with higher aspect ratios at constant film thickness. The better thermoformablity of the films filled with almond shells could be explained by the fact that the addition of a spherical particle has lower negative effects on the flowability of the system than the addition of particles with a larger aspect ratio. The influence of carbon fiber on the elongation behavior of polyethylene is studied in [24], which is rather a trial-and-error investigation. In addition, the evaluation of the components does not include an evaluation of the strain and wall thickness distribution. In current investigations of Landsecker, the influence of graphite particles on the elongation behavior of high-impact polystyrene and the wall thickness distribution of $800 \mu \mathrm{m}$ thick films is shown [25-26]. A good thermoformability was shown mainly for films filled with spherical graphite particles, whereas films filled with plate-shaped particles exhibited a reduced thermoformability. Also an increasing filler contents were related to reduce the formability. In further investigations Landsecker found out that that a higher viscous matrix and the addition of graphite flakes with a higher aspect ratio significantly reduce the critical degree of stretching [27].

Within this investigation, the influence of an increasing glass fiber volume-content as well as the effect of radiation crosslinking on the elongation behavior and the wall thickness distribution were examined. It is assumed that both the filler orientation and the radiation crosslinking have a significant influence on the elongation behavior. Overall, it is expected that the radiation crosslinking of the filled films will have a positive effect on the thermoformability. On the one hand, an increase in melt stiffness can be achieved. On 
the other hand, the crack propagation could be stopped by the creation of crosslinking points. With the knowledge gained from the following investigations, general findings on the thermoforming of filled films shall be derived and the process limits of thermoforming shall be extended.

\section{Material and Methods}

\subsection{Used Materials}

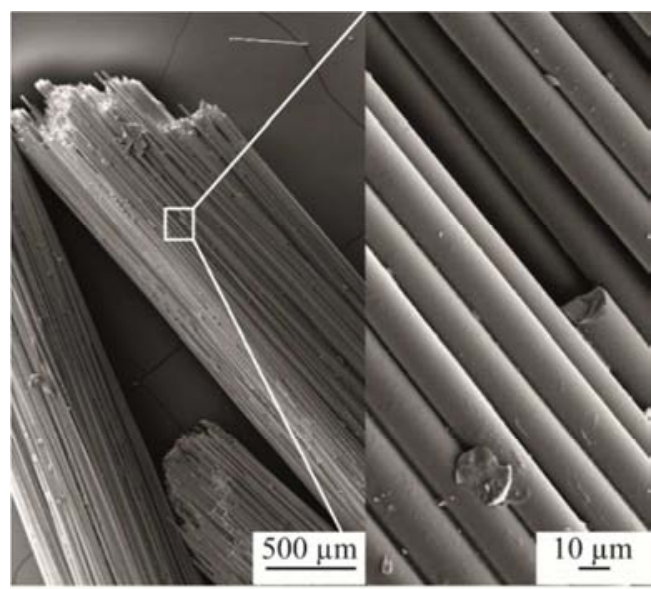

Glass fibers, DS 2200-10P

Figure 1. SEM of the used glass fibers.

As matrix material, a high-density polyethylene (PE-HD) type Lupolen 4261 AG Q 469 (LyondellBasell Industries N.V., Rotterdam, Netherlands) was used for the investigation. The matrix material has a melting peak temperature of $130^{\circ} \mathrm{C}$ and a density of $0.93 \mathrm{~kg} / \mathrm{m}^{3}$. Own measurements and data sheet information are in good accordance. Glass fibers of type DS 2200-10P (3B - the fiberglass company, Binani Industries Ltd, Battice, Belgium) were chosen as filler, which have an original length of $4 \mathrm{~mm}$ and a diameter of $10 \mu \mathrm{m}$. Figure 1 shows a scanning electron micrograph (SEM) with $20 \mathrm{x}$ (left) respectively $500 \mathrm{x}$ (right) magnification of the used filler. In Figure 1 (left) the fiber bundles can been seen, Figure 1 (right) displays the single fibers enlarged. According to the supplier's specification, the glass fibers are coated with a resin system that is compatible with the chosen matrix material. The glass fibers have a smooth surface and the diameters are in accordance to the data sheet. The entire length $(4 \mathrm{~mm})$ of the original glass fibers cannot be monitored in the SEM.

\subsection{Compounding, Extrusion and Electron-beam Irradiation}

For the characterization of the thermoforming process, 550 $\mu \mathrm{m}$ thick films with different volume contents of glass fibers were produced. Therefore, compounds with 7.5 vol.- $\%, 10$ vol.- $\%$ and 15 vol.- $\%$ glass fiber content were produced using a twin screw extruder (Leistritz Extrusionstechnik $\mathrm{GmbH}$, Nuremberg, Germany). The processing parameter of the compounding are shown in Table 1. An increasing temperature profile towards the nozzle was used, where the nozzle temperature was set to $230^{\circ} \mathrm{C}$. Furthermore, the volumetric flow rate was adjusted to $7 \mathrm{~kg} / \mathrm{h}$. For the following extrusion process, a single-screw extruder (Dr. Collin GmbH, Ebersberg, Germany) with a screw diameter of $30 \mathrm{~mm}$, a coat hanger die with a width of $250 \mathrm{~mm}$ and an adaptable thickness adjustment was used. The processing parameters of the extrusion process are also indicated in Table 1.

Table 1. Compounding and extrusion parameters.

\begin{tabular}{llll}
\hline & Unit & Compounding parameters & Extrusion parameters \\
\hline Barrel temperature & ${ }^{\circ} \mathrm{C}$ & $200-230(\mathrm{Z} \mathrm{1}-\mathrm{Z} \mathrm{9})$ & $180-250(\mathrm{Z} 1-\mathrm{Z} 4)$ \\
Die temperature & ${ }^{\circ} \mathrm{C}$ & 230 & 240 \\
Chill-Roll temperature & ${ }^{\circ} \mathrm{C}$ & - & 80 \\
Screw-speed & $1 / \mathrm{min}$ & 120 Screw & $80_{\text {Side feeder }}$ \\
Haul off-speed & $\mathrm{m} / \mathrm{min}$ & - & 88 \\
\hline
\end{tabular}

For the electron-beam irradiation, the films were sent to BGS Beta-Gamma-Service GmbH \& Co. KG (Wiehl, Germany). There the .electron-beam irradiation was conducted with a $10 \mathrm{MeV}$ electron accelerator. Two different irradiation doses, $66 \mathrm{kGy}$ and $132 \mathrm{kGy}$, were chosen. In order to keep the thermal load of the extruded film low, the electron-beam irradiation was carried out in two or four individual steps of $33 \mathrm{kGy}$ each.

\subsection{Film Properties}

\subsubsection{Characterization of the Filler Content and Degree of Crosslinking}

According to DIN EN ISO 1172, the glass fiber content was determined. During the extrusion processes, a total number of 8 samples was taken. At the extruded films, the samples were extracted at the edge and in the middle of the films. Afterwards, the samples were heated in a microwave furnace (Phoenix SAS, CEM GmbH, Kamp-Lintfort, Germany) for 25 minutes at $400^{\circ} \mathrm{C}$ in a ramp-heating program, followed by 50 minutes at $625^{\circ} \mathrm{C}$. With the help of this temperature profile it is possible to separate the decomposition of carbon black and polymer [28]. While all polymers pyrolyze between $400^{\circ} \mathrm{C}$ and $600^{\circ} \mathrm{C}$, carbon black components stay stable in such conditions. The evaluation of the filler content should ensure that during the extrusion process fillers are well distributed in the extruded film.

For the determination of the degree of crosslinking after the electron beam irradiation, solvent extraction according to DIN EN 579 was used. First, the specimens were boiled for 8 $\mathrm{h}$ in a mixture of xylene and 1\% [2,2 methylene-bis-(4methyl-6-tert-butylphenol)] to solve the non-crosslinked parts. Afterwards, the remaining mass was filtered through a 
glass frit (POR2, pore size $40-100 \mu \mathrm{m}$ ) and then dried for 8 $\mathrm{h}$ at $140^{\circ} \mathrm{C}$. In a subsequent step, an incineration according to DIN EN ISO 1172 was carried out in order to separate the fillers from the matrix and to determine the degree of crosslinking of the matrix. Three individual measurements were used for evaluating the so called gel value according to equation (1).

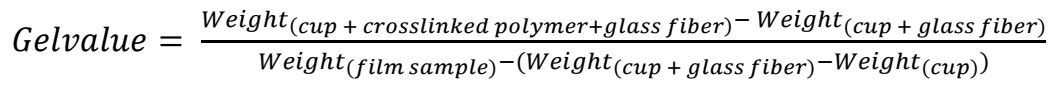

\subsubsection{Mechanical Film Properties}

Since the stiffness behavior of the specimens has an enormous influence on the forming behavior, dynamic mechanical analysis (DMA) as well as tensile tests were carried out to determine the stiffness of the film. DMA investigations were performed to characterize the temperature-dependent stiffness behavior. Tensile tests were conducted to analyze the Young's modulus at $23^{\circ} \mathrm{C}$ and $50 \%$ relative humidity. For the DMA measurements, a RSA-G2 Solids Analyzer (TA Instruments Inc., Eschborn, Germany) was used. The temperature behavior is plainly influenced by the used fillers and filler content as well as the crosslinking process. The temperature range in the DMA was set from $40^{\circ} \mathrm{C}$ to $160^{\circ} \mathrm{C}$ and the frequency to $1 \mathrm{~Hz}$. The specimens have a length of $40 \mathrm{~mm}$ and width of $5 \mathrm{~mm}$ and were taken from the center of the film in and perpendicular the extrusion direction.

According to DIN EN ISO 572-3, uniaxial tensile tests were carried out using an Instron 5948 MicroTester tensile testing machine (Instron $\mathrm{GmbH}$, Darmstadt, Germany). The used tensile bars type $1 \mathrm{~B}$ with a length of $38 \mathrm{~mm}$ and width of $5 \mathrm{~mm}$ (scaling 1:4) were milled out of the center of the film specimens in extrusion direction (i.e.) and perpendicular to extrusion direction (p.e). The strain up to $50 \%$ elongation for evaluating the Young's modulus was measured optically using an Advanced Video Extensometer (Instron $\mathrm{GmbH}$, Darmstadt, Germany), the technical strain of more than $50 \%$ was measured over the traverse path. The test speed for determination of the Young's modulus was set to 0.2 $\mathrm{mm} / \mathrm{min}$. Afterwards the tensile test was continued with a speed of $10 \mathrm{~mm} / \mathrm{min}$.

\subsubsection{Optical Analysis}

The distribution of the glass fibers over the cross-section of the film was analyzed with the help of bright field micrograph images at 20x magnification with a microscope of type Axio Imager M2m (Carl Zeiss AG, Oberkochen, Germany). The cross-section of the films were embedded in epoxy, grinded and polished. Reflecting microscopy was also used to measure the length of the glass fibers before the compounding and extrusion process. For this purpose, the glass fibers were placed on a microscope slide and measured under reflected light by the use of Axio Imager M2m (Carl Zeiss AG, Oberkochen, Germany).

For analyzing the bonding quality of the used glass fibers to the polymer matrix, SEMs were taken by a scanning electron microscope of the type Gemini Ultra-Plus (Carl Zeiss AG, Oberkochen, Germany) at $350 \mathrm{x}$ magnification. All specimens, non-irradiated as well as the electron irradiated, were broken in direction of extrusion in a liquid nitrogen atmosphere. The orientation of the glass fiber is parallel to the fractured surface.

\subsection{Thermoforming Process}

The thermoforming tests were conducted at a single station vacuum forming machine type Berg Mini M3 (Berg Engineering $\mathrm{GmbH}$, Berlin, Germany). For all tests, the machine parameters like mold speed, mold temperature and forming temperature were kept constant. The heating process was carried out with an upper and lower bank of quartz radiant heaters of type SQE 80x60, $150 \mathrm{~W}$ (Friedrich Freek $\mathrm{GmbH}$, Menden, Germany). For the thermoforming process, the forming temperature $\mathrm{T}_{\mathrm{f}}$ was set to about $150^{\circ} \mathrm{C}$ in order to ensure that the films are in a thermos-elastic state with high melt stiffness at the same time. The mold speed was approximately $140 \mathrm{~mm} / \mathrm{s}$ and the mold temperature $100^{\circ} \mathrm{C}$.

Cylindrical rotational symmetrical male molds made of aluminum were used to evaluate the elongation and the wall thickness distribution. Within these molds, a uniform elongation of the fiber filled films in all directions are ensured and thus no influence of the mold geometry on the elongation behavior is induced. The mold height varies between $20 \mathrm{~mm}$ (areal draw ratio $\mathrm{R}_{\mathrm{a}}=1.3$ ), $30 \mathrm{~mm}$ (areal draw ratio $R_{a}=1.5$ ) and $50 \mathrm{~mm}\left(\right.$ areal draw ratio $\left.R_{a}=2.0\right)$ to evaluate the influence of different areal draw ratios on the elongation behavior and to better depict process limits. For a better understand, the thermoforming molds are illustrated schematically in Figure 2. Before thermoforming, a coordinate system was applied to the center of the used film. The coordinate axes $\mathrm{x}$ and $\mathrm{y}$, as well as the angle bisectors $\mathrm{u}$ and $\mathrm{w}$ were were added on the extruded films. The $\mathrm{x}$-axis corresponds to the extrusion direction (i.e.), whereas the yaxis perpendicular to the extrusion direction (p.e.) of the film. When evaluating the wall thicknesses and the elongations, the glass fibers are perpendicular to the radial strain in the ydirection and parallel to it in the x-direction. The distance between the points for determination of the elongation as well as the wall thickness was set to $10 \mathrm{~mm}$. The radial elongation distribution could be determined by measuring the line pitch before and after thermoforming. The so called Cauchy strain was calculated according to the equation (2):

$$
\text { Cauchy strain }=\frac{\text { Length after Thermoforming }- \text { Length before Thermoforming }}{\text { Length before Thermoforming }}
$$

The wall thickness distribution is measured by using a Magna-Mike 8500 thickness gauge measurement system (Olympus 
Deutschland GmbH, Hamburg, Germany). Therefore, the given points were measured before and after thermoforming. Equation 3 shows the determination of the wall thickness reduction.

$$
\text { Wall thickness reduction }=\frac{\text { Film thickness after thermoforming-Film thickness before thermoforming }}{\text { Film thickness before thermoforming }}
$$

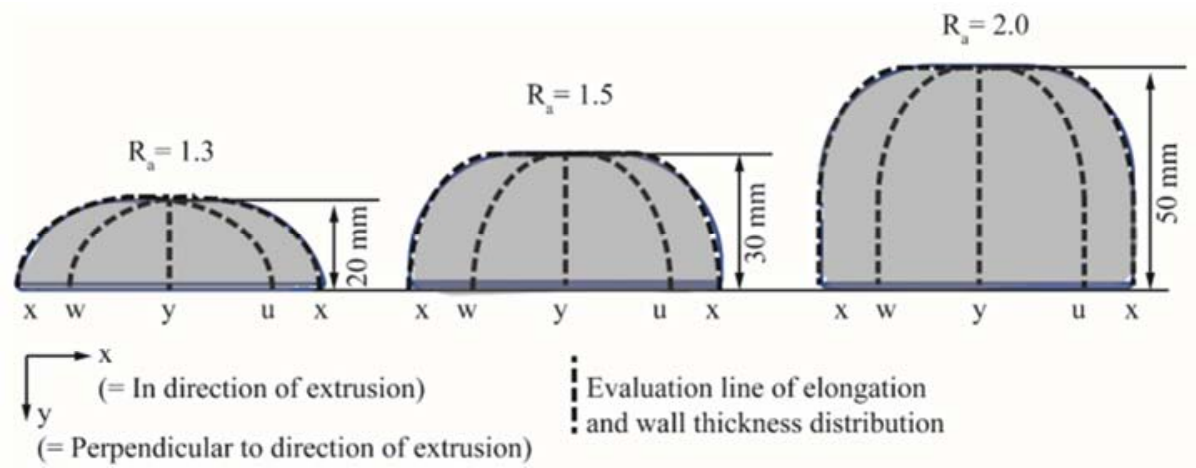

Figure 2. Schematic illustration of the thermoforming molds with the used areal draw ratios $R_{a}$ and the evaluation lines of the elongation and the wall thickness distribution.

\section{Results and Discussion of the Film Properties}

\subsection{Filler Length Distribution}

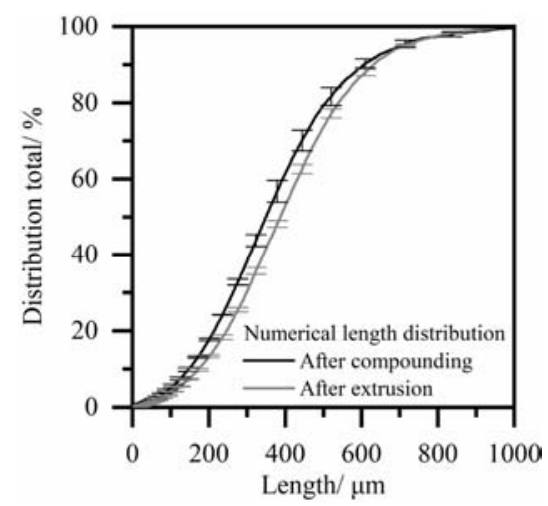

Figure 3. Distribution of the fiber length after compounding and extrusion.

The analysis of the particles size (Figure 3) shows that the compounding and extrusion processes have a major influence on the distribution of the fiber length. The original length of the fillers of $3.4 \pm 0.1 \mathrm{~mm}$, which was measured under the reflected light microscope, was clearly reduced by repeated processing. According to the numerical length distribution, $90 \%$ of the glass fibers are shorter than $600 \mu \mathrm{m}$, which is equivalent to a reduction in length of $75 \%$. Thus, by definition these are short glass fiber reinforced films [29]. With increasing aspect ratio of the fiber particles, the thermoformability could be made more difficult. The fibers can no longer slip against each other, but instead interlocking between the individual particles can occur, causing an elongation impediment. Landescker et al. also confirm that particles with a reduced aspect ratio have a more favorable effect on thermoforming behavior as particles with a high aspect ratio $[25,26]$.

\subsection{Filler Content and Crosslinking Degree}

The evaluation of the filler content after the extrusion process shows that the target content of the filler has been reached. For films filled with 7.5 vol.- $\%$ glass fibers, the measured filler content was $7.5 \pm 0.1$ vol.- $\%$. The measured filler content for films filled with 10 vol.- $\%$ glass fibers was $10.2 \pm 0.3$ vol.- $\%$ and for films filled with 15 vol.- $\% 15.1 \pm$ 0.01 vol.- $\%$.

The distribution of the glass fibers and the increasing filler content can be seen over the cross-section of the film viewed under the bright field microscope. All films were cut perpendicular to direction of extrusion. Typical distributions of the fillers across the film cross-section are shown in Figure 4. A clear orientation of the fibers in extrusion direction is recognizable. Further, a homogeneous distribution of the fillers over the film cross-section can be seen for all used filler contents.
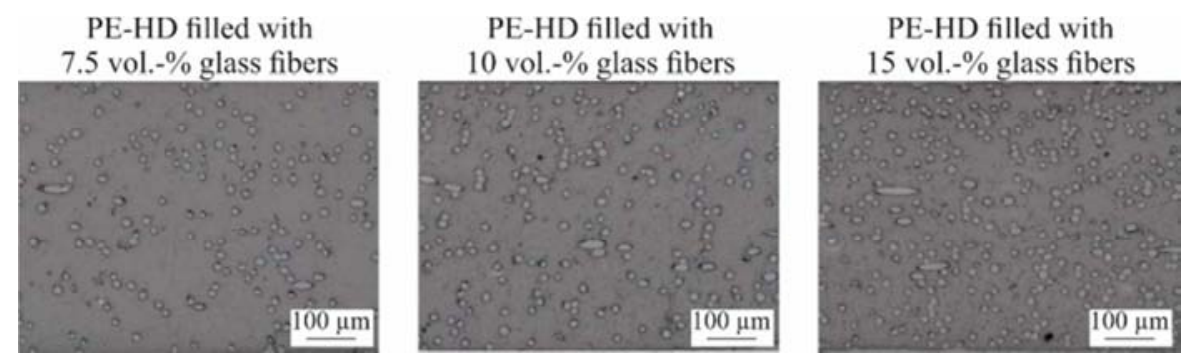

Figure 4. Bright field micrographs of the cross section perpendicular to the extrusion direction of the glass fiber filled films with the used filler contents. 
The results of the analysis of the glass fiber content as well as for the gel value are shown in Table 2. The results of the gel value analysis show that the degree of crosslinking is around 45 - 50 for an irradiation dose of $66 \mathrm{kGy}$ and about 70 for an irradiation dose of $132 \mathrm{kGy}$, irrespective of the filler content. The gel values of the unfilled PE-HD samples irradiated with $132 \mathrm{kGy}$ are in good agreement with analysis by Manas et al. [30], who also investigated the influence of increasing irradiation dose on the gel value of PE-HD. Manas et al. [30] also showed an increasing gel value for glass fiber filled polyamide 6 compared to the virgin matrix material. An explanation for the increase in the gel values cannot be found in this investigation. Reason for an increasing gel value of the glass fiber filled films compared to unfilled PEHD could be the modification of the superstructures in the polymer [9]. The larger aspect ratio of the glass fibers may contribute to an increasing gel value. In further investigations, the extent to which the aspect ratio of the used fillers influences the gel value still has to be clarified.

Table 2. Results of glass fiber content and gel value analysis.

\begin{tabular}{|c|c|c|c|c|}
\hline & Glass fiber content & Measured glass fiber value & $\begin{array}{l}\text { Gel value for an irradiation dose } \\
\text { of } 66 \mathrm{kGy}\end{array}$ & $\begin{array}{l}\text { Gel value for an irradiation dose of } \\
132 \mathrm{kGy}\end{array}$ \\
\hline \multirow[t]{5}{*}{ Unit } & vol.- $\%$ & vol.- $\%$ & - & - \\
\hline & 0 & 0 & $44 \pm 0.9$ & $65 \pm 2$ \\
\hline & 7.5 & $7.5 \pm 0.1$ & $45 \pm 1.8$ & $70 \pm 1.1$ \\
\hline & 10 & $10.2 \pm 0.3$ & $50 \pm 1.6$ & $71 \pm 1.8$ \\
\hline & 15 & $15.1 \pm 0.01$ & $48 \pm 0.7$ & $67 \pm 0.5$ \\
\hline
\end{tabular}

\subsection{Stiffness of the Extruded Sheets}

In Figure 5, the influence of an increasing filler content as well as an increasing irradiation dose on the storage modulus are presented. In the temperature range from $-40^{\circ} \mathrm{C}$ to approximately $125^{\circ} \mathrm{C}$, the storage module is almost independent of the irradiation dose level. Above a temperature of approximately $125^{\circ} \mathrm{C}$, a melting of the material occur. From this point on, a distinct effect of radiation crosslinking on the stiffness of the material is visible. The increased melt stiffness of the crosslinked samples can be explained by an increased number of junction points resulting from the energy input during the electron beam irradiation process [9]. In the thermoforming process, an increased melt stiffness represents an advantage because it prevents extreme sagging of the film and thus damage to machine components such as radiant heaters [31]. The impact of increased melt stiffness on the forming process is evaluated in the following. On the one hand, the increased stiffness can lead to an increased forming window, since slippage of the molecule chains from one another is reduced and thus failure of the films can be prevented. On the other hand, too high melt stiffness can also result in a restriction of the molecular chain mobility, which causes the films to tear. The influence of fiber orientation caused by the extrusion process on the storage modulus is also visible. In the extrusion direction, the stiffness of the specimens is higher than perpendicular to the extrusion direction. An increase of the stiffness in fiber orientation can also be observed in the analysis of tensile tests under standard climate condition $23^{\circ} \mathrm{C} / 50 \%$ relative humidity. This is due to the clearly higher Young's modulus of the fibers compared to the matrix material which clearly influences the overall stiffness in fiber direction, whereas orthogonal to this there is no affect.
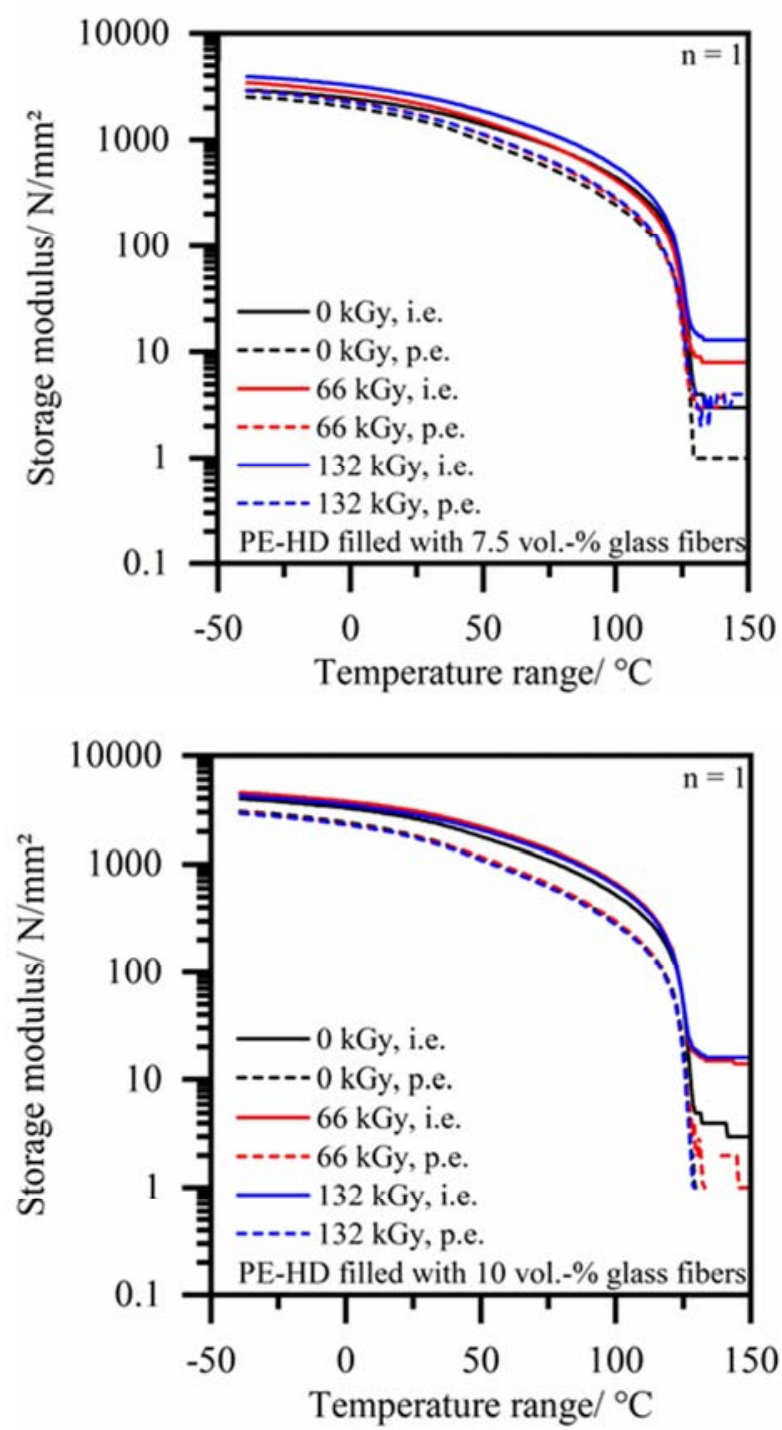


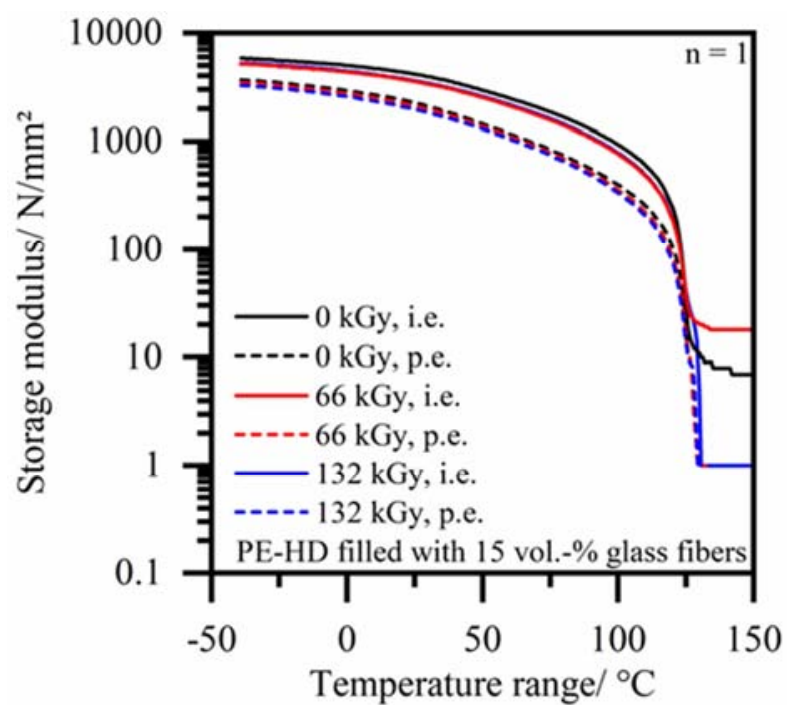

Figure 5. Influence of irradiation doses, filler content and temperature on the storage modulus of the extruded films.

The evaluation of the tensile tests shows that the addition of glass fibers has an enormous effect on the Young's modulus of PE-HD (unfilled: $640 \pm 20 \mathrm{~N} / \mathrm{mm}^{2}$ ), Figure 6 . The reinforcing effect of the glass fibers can be observed especially in the extrusion direction, which is already known form the literature [32, 33]. By adding 10 vol.-\% glass fibers, an increase of the Young's modulus in the direction of extrusion of 1.5 times $\left(2586 \pm 485 \mathrm{~N} / \mathrm{mm}^{2}\right)$ compared to the Young's modulus of films filled with 7.5 vol.-\% $(1822 \pm 294$ $\mathrm{N} / \mathrm{mm}^{2}$ ) is achieved. By adding 15 vol.- $\%$ glass fibers, the stiffness is 2 times higher $\left(3688 \pm 265 \mathrm{~N} / \mathrm{mm}^{2}\right)$ than the stiffness of films filled with 7.5 vol.- $\%$ glass fibers. Evaluating the influence of the irradiation dose level is examined, no visible effect of the irradiation dose on the Young's modulus can be determined for films filled with the different glass fiber contents. The results of the mechanical test under standard climate conditions $\left(23^{\circ} \mathrm{C}, 50 \%\right.$ humidity $)$ are in good agreement with the results of the DMA measurements over the extended temperature range from $40^{\circ} \mathrm{C}$ to $150^{\circ} \mathrm{C}$.

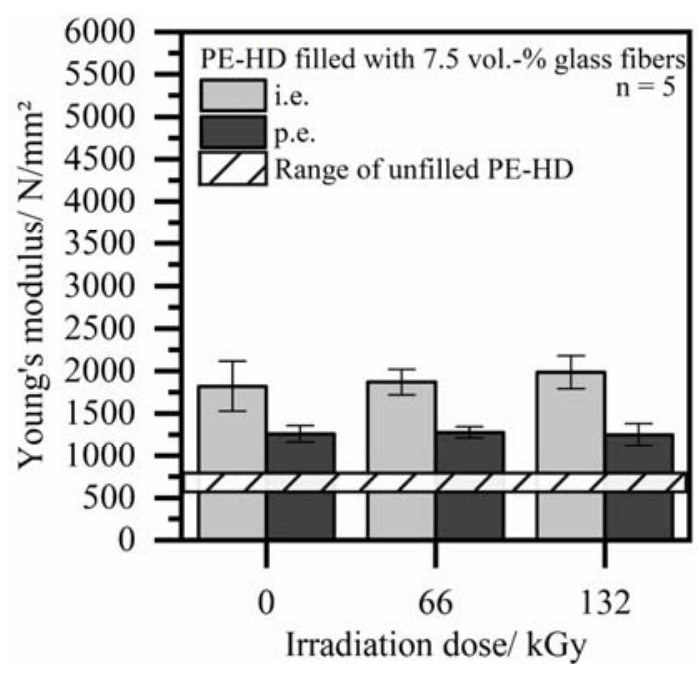

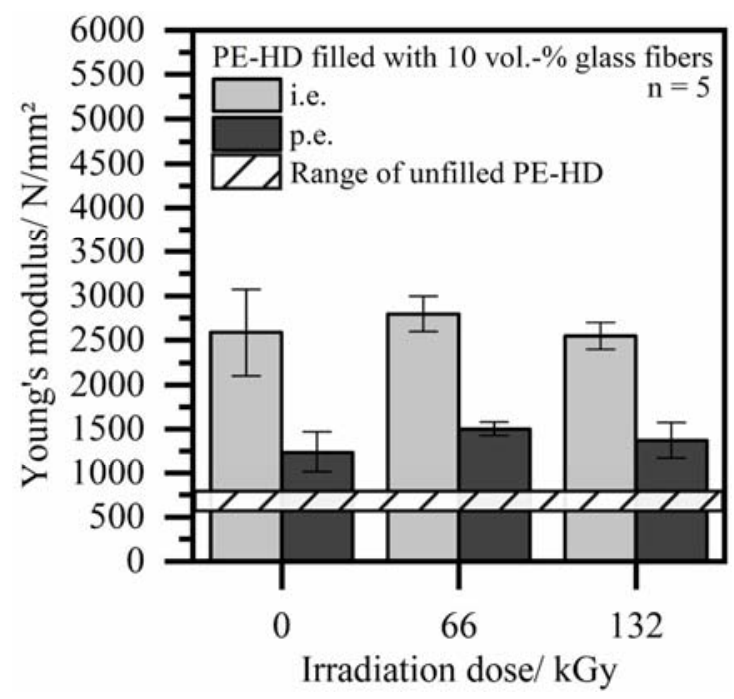

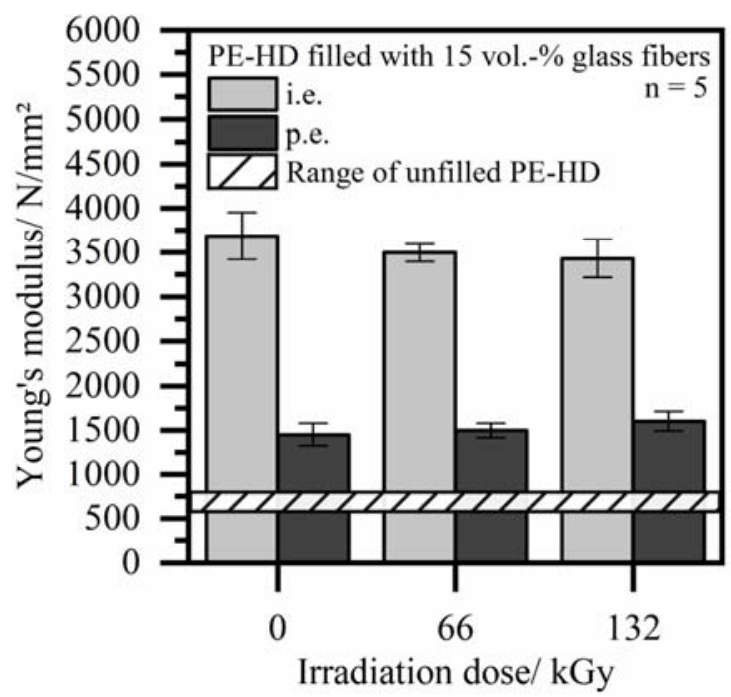

Figure 6. Influence of irradiation dose, filler content and direction of extrusion on the Young's modulus of the extruded films.

\subsection{Optical Analysis of the Fracture Behavior}

The fracture surface of the filled films with different filler content and irradiation dose is shown in Figure 7. As the filler-matrix interaction was particularly focused in the scanning electron microscope, all films were broken in extrusion direction. Independent on the filler degree, the fracture surface seems to be rather brittle. Although, according to the manufacturer, the coating is compatible with the matrix material used, good bonding seems not to be achieved. For both non-irradiated and irradiated films, the glass fibers are neither enclosed with matrix material nor bonding is visible. This is in contrast to the literature [9], where crosslinking improves the filler matrix adhesion. One reason for this fracture behavior could be the low temperature, which was used for the break. Furthermore, it is also known from literature that the bonding of glass-like fillers is always a challenge [20]. Nevertheless, an improved filler matrix adhesion should be content of further investigations. 

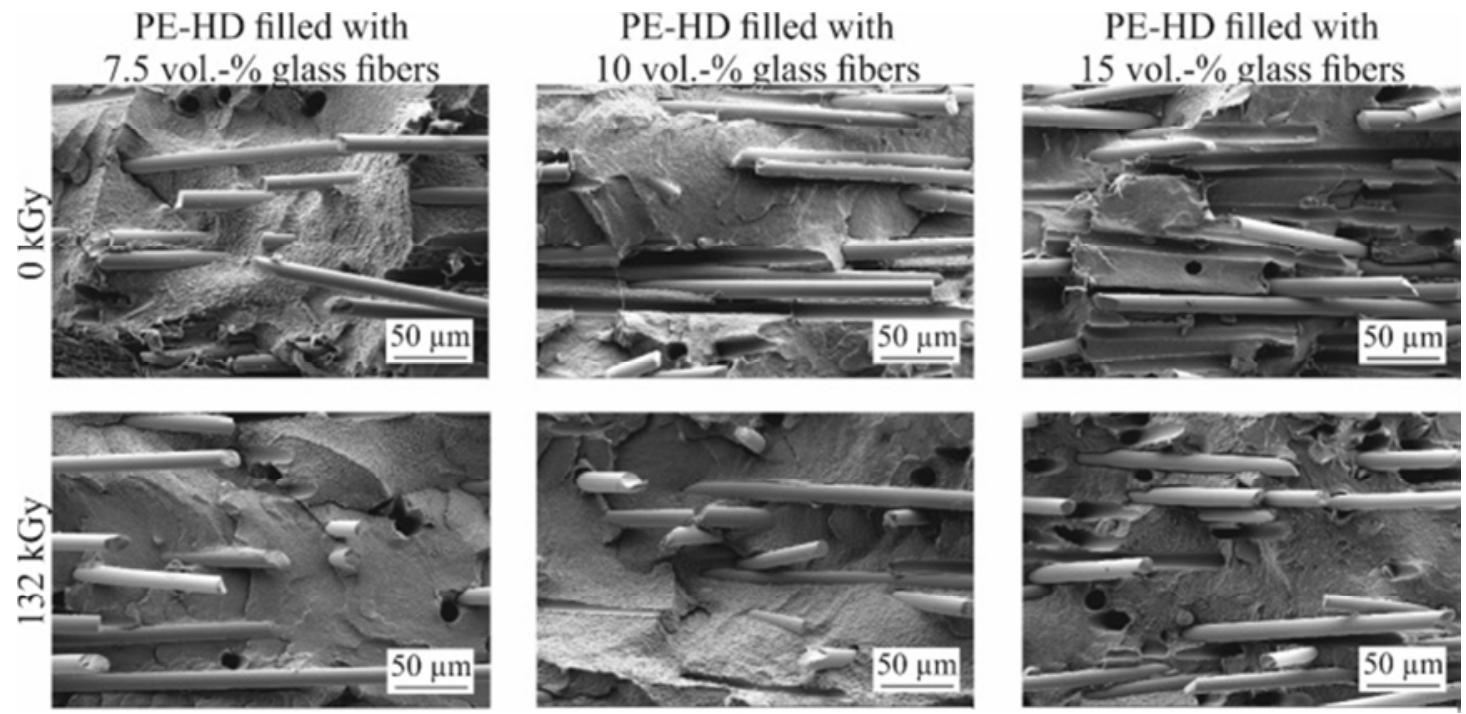

Figure 7. SEM of cryogenically fractured films in dependence of filler content and irradiation, fractured in direction of extrusion.

\section{Results of the Thermoforming Process}

\subsection{Evaluation of the Directional Dependence on the Elongation of Glass Fiber Filled Films}

Since the direction dependency has an enormous influence on the stiffness of fiber filled systems (compare Figure 6), the orientation of the fiber has also to be taken into account in the evaluation of the elongation. Figure 8 shows the effect of fiber orientation on the elongation behavior of the fiber filled films with different fiber contents for a small $\left(\mathrm{R}_{\mathrm{a}}=1.3\right)$ and a large $\left(R_{a}=2.0\right)$ areal draw ratio. As the effect of fiber

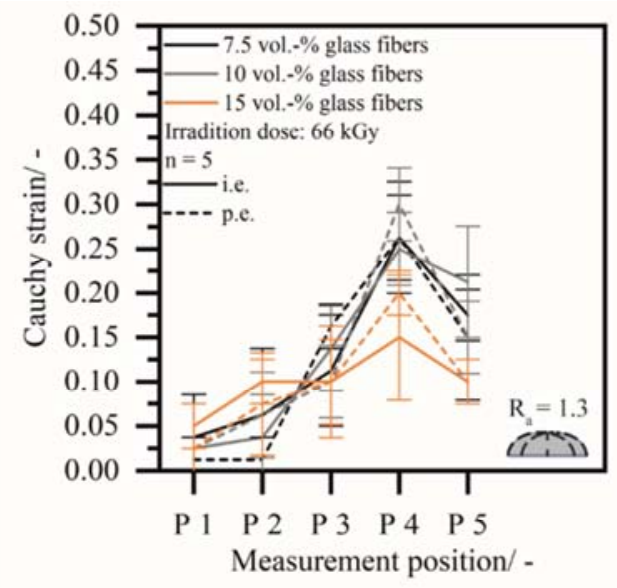

orientation is independent of the irradiation dose used, only the elongations of filled films irradiated with $66 \mathrm{kGy}$ are shown in Figure 8. At a small areal draw ratio of 1.3, there is no visible influence of the fiber orientation on the elongation behavior. Furthermore, the maximum elongation for all filled systems is about 0.2 , independent of the filler content $(7.5$ vol- $\%$ and 10 vol.- $\%$ ). For films filled with 15 vol.- $\%$ glass fibers, a reduced maximum elongation (Cauchy strain $=0.1$ ) can be observed. This can possibly be attributed to the higher stiffness of the films. Since only small elongation occurs at a low areal draw ratio $\left(\mathrm{R}_{\mathrm{a}}=1.3\right)$, no difference between noncrosslinked and crosslinked specimens can be detected.

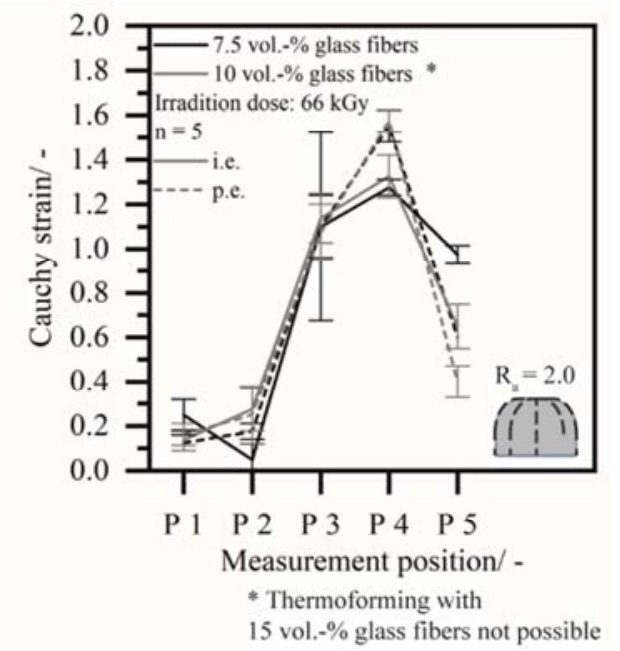

Figure 8. Chauchy strain development of 7.5 vol.-\%, 10 vol.\% and 15 vol.-\% glass fiber filled PE-HD films, irradiated with $66 \mathrm{kGy}$, formed at an areal draw ratio of 1.3 and 2.0 .

In case of a higher areal draw ratio of 2.0 , the influence of the fiber orientation on the elongation behavior becomes apparent for glass-fiber filled films with 7.5 vol.- $\%$ and 10 vol.- $\%$. With an orientation of the fibers perpendicular to the direction of elongation (p.e.), the elongations achieved are about $20 \%$ higher than with an orientation of the fibers in the direction of elongation (i.e.). One reason for this could be the influence of the fiber orientation on the elongation behavior. If the fibers are perpendicular to the direction of elongation, the matrix carries the larger part in the development of the elongation. The maximum elongation is reduced when the fibers are oriented in the direction of elongation. When the 
fibers are oriented in the direction of elongation, the reinforcement effect of the fibers appears which could reduce the maximum reachable elongation. Maybe there is also fiber entanglement that prevents the elongation process. Irradiated films filled with 15 vol.- $\%$ cannot be formed as tearing of the films occurs, Figure 8 . The influence of the irradiation dose level on the elongation behavior is less at a high surface aspect ratio of $R_{a}=2.0$. A similar behavior occurs in the elongation curve for a higher crosslinking dose of $132 \mathrm{kGy}$. It should be noted that investigations with a smaller grid or with the aid of digital image correlation are planned as the distance between point 3 and 4 is rather wide after the thermoforming process. In addition, further investigations should be carried out, which also consider the bisecting angles ( $u$ and $w$ ) in the coordinate system.

\subsection{Evaluation of the Influence of Different Irradiation Doses on the Wall Thickness Distribution}

The general development of the wall thickness change is similar for all specimens regardless of the filling degree due to the selected mold geometry. Therefore, the influence of a varied irradiation dose level is evaluated exemplarily for a filling degree of 10 vol.- $\%$ and an areal draw ratio of 1.3. A local examination of the wall thickness reduction across the entire cross-section is carried out. For a glass fiber volume content of 10 vol.- $\%$ and a low areal draw ratio of 1.3 , the

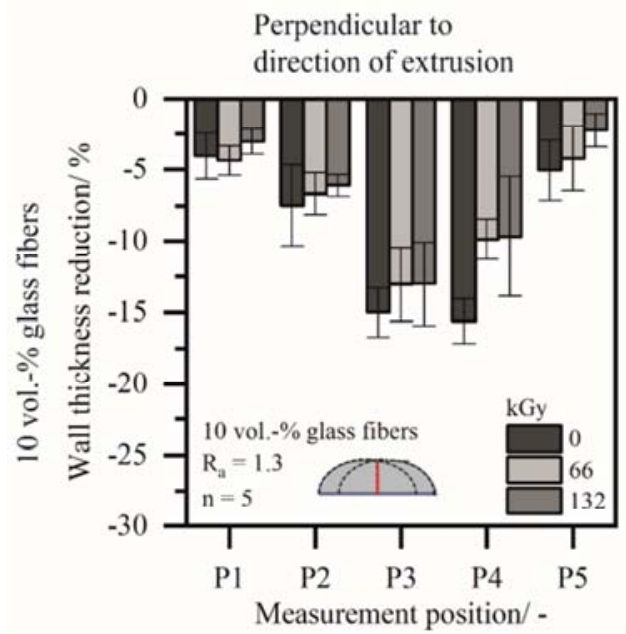

wall thickness distribution is shown in Figure 9. By evaluating the wall thickness reduction, it is conspicuous that an enormous difference in the wall thickness reduction depending on the fiber orientation appears, especially for the non-crosslinked specimens. For example, at point 3 the wall thickness is reduced by $15 \pm 2 \%$ perpendicular the extrusion direction, while in the extrusion direction only $11 \pm 2 \%$ wall thickness reduction appears. In addition to reduced elongation, it seems that the fibers also contribute to a reduced wall thickness change, since the interlocking of individual fibers reduces elongation and thus also the wall thickness decrease. For radiation crosslinked samples, the directional dependence induced by fiber addition appears to be less (e.g. at point 4 with $66 \mathrm{kGy}:-12 \pm 4 \%$ i.e. and $13 \pm$ $3 \%$ p.e.). The influence of the irradiation dose level ( $66 \mathrm{kGy}$ or $132 \mathrm{kGy}$ ) on the reduction of the wall thickness seems to be rather small for all used areal draw ratios, shown exemplarily in Figure 9 for the ratio of 1.3. The high standard deviation could be induced by the process. The forming process may cause internal fibers to be pushed to the surface and thus generate a higher surface roughness, which in turn would lead to variations in the thickness measurement. Furthermore, the wall thickness change should also be correlated with the surface roughness in further investigations.

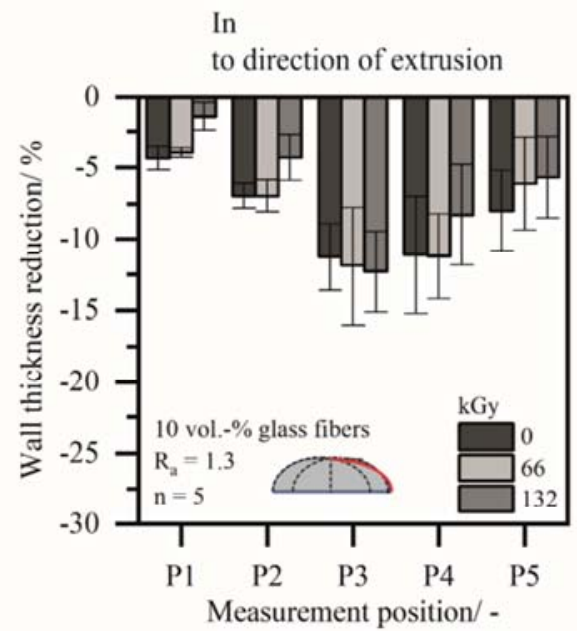

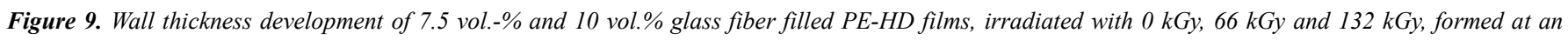
areal draw ratio of 1.3 .

Since the maximum elongation is present between points 3 and 4 , the maximum wall thickness reduction is evaluated at point 3. Table 3 shows the results of the wall thickness reduction of evaluation point 3 for all three areal draw ratios, depending on the filler content and orientation as well as the irradiation dose level. For small areal draw ratios (1.3 and 1.5) no difference in the maximum wall thickness reduction caused by the irradiation dose levels and filler content can be determined. This is mainly due to the low stretching and thus low wall thickness reduction of the specimens. With increasing areal draw ratio (2.0), the forming of noncrosslinked specimens is no longer possible, regardless of the filler content. Forming of radiation crosslinked samples at an areal draw ratio of 1.5 is possible for all filler degrees, independent of the irradiation dose.

At a higher areal draw ratio $\left(\mathrm{R}_{\mathrm{a}}=2.0\right)$, the influence of radiation crosslinking is apparent slightly, so the wall thickness reduction at point 3 for specimens irradiated with $66 \mathrm{kGy}$ is slightly higher than that of specimens irradiated with $132 \mathrm{kGy}$ (7.5 vol.- $\%$, p.e., $66 \mathrm{kGy}=-71 \pm 9 \%$, 7.5 vol.$\%$, p.e., $132 \mathrm{kGy}=-65 \pm 4 \%$ ). Whereas non-crosslinked films cannot be formed, crosslinking enables the thermoforming of thin films with 7.5 vol.- $\%$ and 10 vol.- $\%$ glass fiber fillers. Only at a filler content of 15 vol.- $\%$, 
crosslinked samples cannot be formed. This may be due to the high stiffness of the specimens, which causes the films to tear despite radiation crosslinking and thus inhibits the forming process.

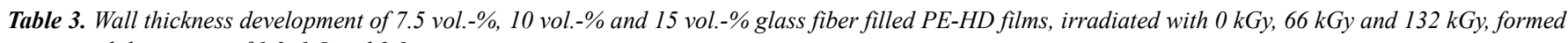
at an areal draw ratio of $1.3,1.5$ and 2.0 .

\begin{tabular}{|c|c|c|c|c|c|c|c|c|c|c|}
\hline \multicolumn{2}{|c|}{ Filler content [vol.-\%] } & 7.5 & & & \multicolumn{3}{|l|}{10} & \multicolumn{3}{|c|}{15} \\
\hline Radiation do & [kGy] & 0 & 66 & 132 & 0 & 66 & 132 & 0 & 66 & 132 \\
\hline \multirow{5}{*}{$\begin{array}{l}\text { Areal draw } \\
\text { ratio }\end{array}$} & 1.3 , i.e. & $-8 \pm 2$ & $-10 \pm 1$ & $-10 \pm 2$ & $-11 \pm 2$ & $-12 \pm 4$ & $-12 \pm 3$ & \multirow[b]{2}{*}{--} & $-9 \pm 1$ & $-17 \pm 7$ \\
\hline & 1.3 , p.e. & & $-13 \pm 3$ & $-14 \pm 5$ & $-15 \pm 2$ & $-13 \pm 3$ & $-13 \pm 3$ & & $-11 \pm 2$ & $-19 \pm 3$ \\
\hline & 1.5 , i.e. & & $-20 \pm 2$ & $-21 \pm 4$ & & $-20 \pm 3$ & $-26 \pm 8$ & & $-15 \pm 3$ & $-16 \pm 2$ \\
\hline & 1.5, p.e. & -- & $-27 \pm 4$ & $-30 \pm 3$ & -- & $-28 \pm 7$ & $-25 \pm 2$ & -- & $-17 \pm 4$ & $-19 \pm 3$ \\
\hline & $\begin{array}{l}2.0, \text { i.e. } \\
2.0, \text { p.e. }\end{array}$ & -- & $\begin{array}{l}-59 \pm 9 \\
-71 \pm 9\end{array}$ & $\begin{array}{l}-55 \pm 3 \\
-65 \pm 4\end{array}$ & -- & $\begin{array}{l}-63 \pm 2 \\
-69 \pm 3\end{array}$ & $\begin{array}{l}-59 \pm 2 \\
-65 \pm 2\end{array}$ & -- & & \\
\hline
\end{tabular}

-: no thermoforming possible

i.e. $=$ in direction of extrusion

p.e. $=$ perpendicular to direction of extrusion

\section{Conclusion}

The influence of increasing filler content and radiation crosslinking on the elongation behavior of filled films in thermoforming is content of this investigation. It can be summarized that especially thermoforming with an increased content of fillers with high aspect ratios represents a challenge at high areal draw ratios. Whereas non-crosslinked glass fiber filled samples are thermoformable only at low areal draw ratios $\left(\mathrm{R}_{\mathrm{a}}=1.3\right)$, radiation crosslinked films can be also formed at higher areal draw ratios $\left(\mathrm{R}_{\mathrm{a}}=1.5\right)$ without difficulties. For high filler contents and high areal draw ratios of 2.0, no forming is possible, although the films have been crosslinked. The influence of irradiation dose height seems to be rather low while an increasing filler content seems to be the more limitation factor. The presence of an increased connection of molecule chain points due to radiation crosslinking seems to be sufficient to widen the process windows of filled films, independent of the radiation dose. This expansion can open up new fields of application for thin films that are mechanical stressed. By adding fibers, considerably greater stiffness can be achieved in and perpendicular to the fiber direction compared to an unfilled film, which also extends the range of applications. Evaluating the wall thickness reduction, there could be no influence of an increasing filler content identified. The elongation behavior seems not to be dependent on the filler content, especially for small areal draw ratios. However, the elongation behavior is dependent of the filler orientation for higher areal draw ratios. Further investigations should focus on the influence of different filler shapes, for example plate like fillers, and different matrix material on the elongation behavior. Since the forming accuracy of radiationcrosslinked films in particular can also related to the degree of crosslinking, this shall be considered in further investigations.

\section{Competing interest}

The authors declare that they have no competing interests.

\section{Acknowledgements}

The authors would like to thank the Deutsche Forschungsgemeinschaft (DFG) for funding the work in the project DR 421/20-1. The authors also extend their gratitude to their industrial partners, BGS Beta-Gamma-Service $\mathrm{GmbH}$ \& Co. KG, Wiehl, Germany for conducting the irradiation of the samples and LyondellBasell, Industries N.V., Rotterdam, Netherlands for providing the material. Further thanks go to Pöppelmann GmbH \& Co. KG Kunststoffwerk-Werkzeugbau (Lohne, Germany), SENOPLAST Klepsch \& Co. GmbH (Piesendorf, Austria) and Teknor Germany $\mathrm{GmbH}$ (Tauberzell, Germany).

\section{References}

[1] Myer Kutz, Applied plastics engineering handbook. Processing, materials, and applications, William Andrew is an imprint of Elsevier, Kidlington, Oxford, United Kingdom, 2016.

[2] P. Schwarzmann, Thermoformen in der Praxis, Hanser, Munich, 2008.

[3] J. L. Throne, Understanding thermoforming, Hanser, Munich, 2008.

[4] S. Engelmann, Advanced thermoforming: Methods, machines and materials, applications and automation, Wiley, Hoboken, NJ, 2012.

[5] H. C. Lau, S. N. Bhattacharya, and G. J. Field, "Influence of rheological properties on the sagging of polypropylene and abs sheet for thermoforming applications," Polymer Engineering and Science, vol. 40, no. 7, pp. 1564-1570, 2004.

[6] M. Yamaguchi and K.-I. Suzuki, "Enhanced strain hardening in elongational viscosity for HDPE/crosslinked HDPE blend. II. Processability of thermoforming," Journal of Applied Polymer Science, vol. 86, no. 1, pp. 79-83, 2002.

[7] M. Yamaguchi, "Rheological properties of linear and crosslinked polymer blends: Relation between crosslink density and enhancement of elongational viscosity," Journal of Polymer Science Part B: Polymer Physics, vol. 39, no. 2, pp. 228-235, 2000. 
[8] A. Charlesby, Atomic radiation and polymers, Pergamon Pr, Oxford u.a., 1960.

[9] K. Makuuchi, Radiation processing of polymer materials and its industrial applications, Wiley, Hoboken, NJ, 2012.

[10] N. Rosenzweig and Narkis, M., Tadmor, Z., "Wall thickness distribution in thermoforming," Polymer Engineering and Science, vol. 19, no. 13, pp. 946-951, 1979.

[11] A. Aroujalian, M. O. Ngadi, and J.-P. Emond, "Wall thickness distribution in plug-assist vacuum formed strawberry containers," Polymer Engineering and Science, vol. 37, no. 1, pp. 178-182, 1997.

[12] M. O. Lai, "Thickness variation in the thermoforming of poly (methyl methacrylate) and high - impact polystyrene sheets," Journal of Applied Polymer Science, no. 7, pp. 1805-1814, 1975.

[13] C. Jobey, N. Allanic, and P. Mousseau, Prediction of thickness distribution of thermoformed multilayer ABS/PMMA sheets, American Institute of Physics Inc, AIP Conference Proceedings 1769, 170033 (2016), 2016.

[14] J. Cha, M. Kim, D. Park et al., "Experimental determination of the viscoelastic parameters of K-BKZ model and the influence of temperature field on the thickness distribution of ABS thermoforming," The International Journal of Advanced Manufacturing Technology, 2019.

[15] J. Holbery and D. Houston, "Natural-fiber-reinforced polymer composites in automotive applications," JOM, vol. 58, no. 11, pp. 80-86, 2006.

[16] G. Lebrun, M. N. Bureau, and J. Denault, "ThermoformingStamping of Continuous Glass Fiber/Polypropylene Composites: Interlaminar and Tool-Laminate Shear Properties," Journal of Thermoplastic Composite Materials, vol. 17, no. 2, pp. 137-165, 2004.

[17] D. Lussier and J. Chen, "Material Characterization of Woven Fabrics for Thermoforming of Composites," Journal of Thermoplastic Composite Materials, vol. 15, no. 6, pp. 497509, 2002.

[18] S. Hineno, T. Yoneyama, D. Tatsuno et al., "Fiber Deformation Behavior during Press Forming of Rectangle Cup by Using Plane Weave Carbon Fiber Reinforced Thermoplastic Sheet," Procedia Engineering, vol. 81, pp. 1614-1619, 2014.

[19] B.-A. Behrens, A. Raatz, S. Hübner et al., “Automated Stamp Forming of Continuous Fiber Reinforced Thermoplastics for Complex Shell Geometries," Procedia CIRP, vol. 66, pp. 113118, 2017.
[20] G. Wypych, Handbook of fillers, ChemTec Publishing, Toronto, 2016.

[21] T. P. Mohan and K. Kanny, "Thermoforming studies of corn starch-derived biopolymer film filled with nanoclays," Journal of Plastic Film \& Sheeting, vol. 32, no. 2, pp. 163$188,2015$.

[22] L. Avérous, C. Fringant, and L. Moro, "Starch-Based Biodegradable Materials Suitable for Thermoforming Packaging," STARCH-STARKE, vol. 53, pp. 368-371, 2001.

[23] E. L. Sánchez-Safont, A. Aldureid, J. M. Lagarón et al., "Biocomposites of different lignocellulosic wastes for sustainable food packaging applications," Composites Part B: Engineering, vol. 145, pp. 215-225, 2018.

[24] O. Ekşi and E. Erdogan, "Effects of manufacturing defects on thermoformed product quality," Usak University Journal of Material Sciences, vol. 3.

[25] K. Landsecker and C. Bonten, "Investigation on the thermoformability of heat conductive plastics," AIP Conference Proceedings, vol. 2055, no. 1, p. 50003, 2019.

[26] K. Landsecker and C. Bonten, "Thermoforming simulation of heat conductive plastic materials using the K-BKZ model," AIP Conference Proceedings, vol. 2065, no. 1, p. 30049, 2019.

[27] K. Landsecker, Zum Thermoformen wärmeleitfäiger Kunststoffe, Institut für Kunststofftechnik, Stuttgart, 2018.

[28] G. W. Ehrenstein, Thermal analysis of plastics: Theory and practice, Hanser; Hanser Gardner, Munich, Cincinnati, 2004.

[29] M. Schoßig, Schädigungsmechanismen in faserverstärkten Kunststoffen. Quasistatische und dynamische Untersuchungen, Vieweg + Teubner, Wiesbaden, 2011.

[30] D. Manas, M. Ovsik, A. Mizera et al., "The effect of irradiation on mechanical and thermal properties of selected types of polymers," Polymers, vol. 10, no. 2, p. 158, 2018.

[31] A. Seefried, Zum Thermoformen von vernetztem Polyamid, Lehrstuhl für Kunststofftechnik, Erlangen, 2015.

[32] G. W. Ehrenstein, Faserverbund-Kunststoffe. Werkstoffe, Verarbeitung, Eigenschaften, Hanser, Munich, 2006.

[33] M. Neitzel, P. Mitschang, and U. Breuer, Handbuch Verbundwerkstoffe: Werkstoffe, Verarbeitung, Anwendung, Hanser, Munich, 2014. 